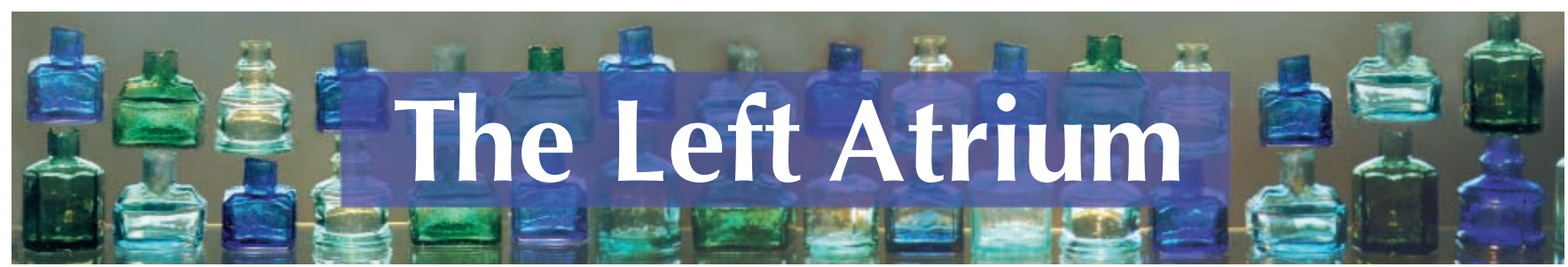

\section{True confessions}

Singular intimacies: becoming a doctor at Bellevue Danielle Ofri

Boston: Beacon Press; 2003

246 pp. \$34.95 (cloth) ISBN 0-8070-7252-4

$\mathrm{H}$ ospitals, as any microbiologist will tell you, are fertile ground. Thus it is, I suppose, that we frequently see new books by freshly minted physicians, wherein these residents-cumattendings relate the experiences and epiphanies by means of which they have become not only better doctors but better human beings. A recent such offering is from Danielle Ofri, an attending physician at Bellevue with an appointment at New York University, who also is editor-in-chief and founder of the Bellevue Literary Review.

Singular Intimacies is well written and replete with examples of situations frequently encountered by clinical clerks and residents. There is the horrible IV start, the difficult intubation and the singularly gut-wrenching unexpected "loss" of a patient. Ofri offers a wonderfully thought-provoking discussion of a physician patient whose apparent denial in the face of serious illness at first stymies her attempts to "reach" him but ultimately comes to be seen as a perhaps not un-useful coping strategy, especially in a world in which an emphasis on "early detection" arguably serves to prolong dying rather than living.

Ofri's literary pretensions are genuine: her book is eminently readable. The anecdotes she relates are at times quite moving, at times less so, but all are illuminated by a certain poetic sensibility. Yet there is something troubling here. I am concerned somewhat by the book's "happy ending," by the fact that if we don't read it carefully we can put it down and feel 酸 good. I have no quibble with the sug焉 gestion that it "is sometimes in the

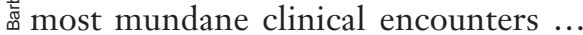

that medicine is most uplifting." And I accept Ofri's contention that she has grown through her training. But we must attend to the fact that, to do so, she needed to "take a break from academic medicine." She notes: "reading, writing, thinking - these were things I hadn't had much time for during residency."

As I approach the end of my own clinical clerkship, and as I move toward my own residency, I cannot fail to note that this book is peppered with descriptions and comments that ought, I think, to raise questions about medical education and training. Ofri recounts endless nights "renewing medication orders, writing notes in the chart that nobody ever read," describes the painful realization that "residents are cheap labor for private attendings" and observes that "staying afloat in the sea of

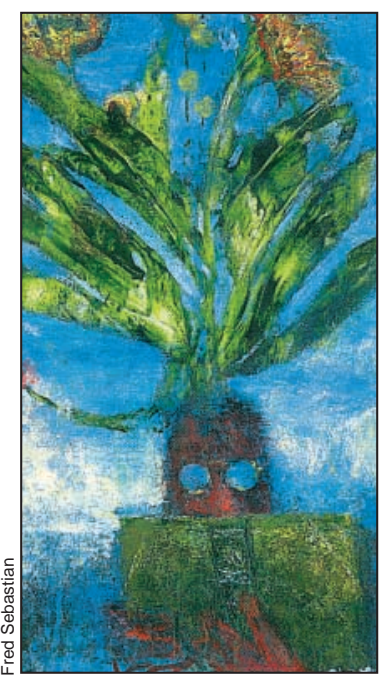
scut $[. .$. leaves] most interns too exhausted to muster any spare neurons for education." She relates hectic evenings when she "raced from one ward to the next, counting the hours until the day."

And then - in one sentence - Singular Intimacies risks becoming yet another affirmation of the status quo: "[b]ut my technical skills improved rapidly because there was so much to do and no one else to do it for me." And, even as I move exhausted from clerkship to internship, my own complaints about thirty-hour shifts and sleep-deprived learning opportunities tend to be couched in only moderately hidden bravado.

Nietzsche wrote somewhere that the things that don't kill us make us stronger. We in the medical community tend, I think, to wear many systemic hardships as badges of honour. In writing and reading books such as this, we need to be careful lest we delude ourselves, by telling one another how much we all grow through the singular intimacies and familiar excesses that are our training programs. If we uncritically "buy" happy endings, the endurance testing that is axiomatic in medical training always can be shown to be "worth it," whether by improving technical skills or enhancing character.

But still Ofri reminds us, "[o]urs is a dangerous profession." She writes poignantly of the suicide of a gruff intensivist and warns of the "Faustian bargain we make when we enter the profession," a compact wherein taking care of others can replace caring for ourselves.

Taking care of others is affirming, rewarding, even ennobling, but it is illusion and charade if it is at the expense of our own health and relationships. If we glorify resident years as periods of singular intimacies, and allow this to blind us to the many correctible excesses of the status quo, we do so at the expense of our patients, and dare I say it, more importantly, of ourselves.

\section{Ted St. Godard}

Med IV

University of Manitoba

Winnipeg, Man. 